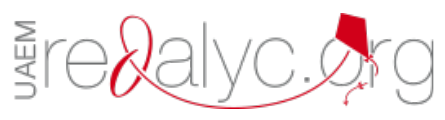

Centro Sur

ISSN: $2600-5743$

compasacademico@icloud.com

Grupo Compás

Ecuador

\title{
Cultura vitivinícola y su desarrollo en la sociedad ecuatoriana
}

Salas Arreaga, Cristina Denise

Cultura vitivinícola y su desarrollo en la sociedad ecuatoriana

Centro Sur, vol. 2, núm. 2, 2018

Grupo Compás, Ecuador

Disponible en: http://www.redalyc.org/articulo.oa?id=588861693002

Esta obra está bajo una Licencia Creative Commons Atribución-NoComercial-SinDerivar 4.0 Internacional. 


\title{
Cultura vitivinícola y su desarrollo en la sociedad ecuatoriana
}

\author{
Wine culture and its development in Ecuadorian society \\ Cristina Denise Salas Arreaga denise_salas@outlook.es \\ Instituto Superior Vicente Rocafuerte, Ecuador \\ http://orcid.org/0000-0003-3456-8131
}

Centro Sur, vol. 2, núm. 2, 2018

Grupo Compás, Ecuador

Recepción: 11 Enero 2017

Aprobación: 31 Octubre 2018

Redalyc: http://www.redalyc.org/ articulo.oa?id $=588861693002$

\section{BY-NC-ND}

Resumen: Los cultivos de uvas han existido mundialmente desde tiempos prehistóricos y posteriormente está costumbre pasó a ser tomada por las antiguas civilizaciones que se fueron desarrollando con el transcurso de los años. Esto no solo ocasionó que se innovaran nuevas formas de sembrar viñedos, sino también provocó que se crearán nuevas cepas de uvas a partir de cepas silvestres. La cultura Vitivinícola se desarrollo en Ecuador con la introducción de vinos importados desde la etapa colonial, el primer vino que se introdujo fue de origen chileno. Luego en los años 90 más países se sumaron a esta competencia como Argentina o Estados Unidos. En la actualidad el vino chileno sigue siendo un fuerte competidor en la industria productora de vinos. Nuestro mercado ecuatoriano cuenta con una amplia variedad de marcas de vinos de buena calidad y el porcentaje de consumo ha ido en aumento con el pasar de los años. En nuestro país existen muchos viñedos, aunque solo dos son los más importantes debido al aporte que han hecho, la diferencia de estos dos viñedos en comparación con los otros viñedos es que ellos se dedican a la cosecha de uvas y elaboración de vinos para la importación y exportación, llegando incluso a ganar reconocidos premios.

Palabras clave: cultura Vitivinícola, viñedos, vinos, cepas, desarrollo.

Abstract: The cultivation of grapes have existed worldwide since prehistoric times and subsequently this custom step to be taken by the ancient civilizations that have developed over the years. This not only resulted in innovate new ways to plant vineyards, but also led to the creation of new strains of grapes from wild strains. Wine culture developed in Ecuador with the introduction of wines imported from the colonial era, the first wine which was introduced was of Chilean origin. Then in the years 90 more countries joined this competition as Argentina or the United States. Currently, the Chilean wine remains a strong competitor in the industry producing wines. Our Ecuadorian market has a wide variety of brands of wines of good quality and the percentage of consumption has been increasing over the years. In our country, there are many vineyards, although only two are the most important because of the contribution they have made, the difference of these two vineyards in comparison with the other vineyards is that they are dedicated to the harvest of grapes and wines for the import and export, even going so far as to earn recognized awards.

Keywords: Wine culture, vineyards, wines, strain, development.

\section{INTRODUCCIÓN}

Las cosechas de uvas son uno de los cultivos más antiguos globalmente, éstos existían desde tiempos prehistóricos y después está costumbre alcanzó hasta las antiguas civilizaciones, por ende con el transcurso del tiempo se han utilizado especies silvestres como punto de partida para la creación de nuevas cepas de uvas. Se conoce que en distintos lugares de la serranía ecuatoriana ya se cultivaban viñedos desde los tiempos coloniales, pese a esto la mayoría de las cosechas de uva para mesa y elaboración 
de vinos proviene de Puerto El Morro, ubicado en la provincia de Santa Elena.

Basado en reemplazar las importaciones y transformar la matriz productiva establecidas por el gobierno, es de vital importancia encontrar nuevas opciones para las cosechas de viñedos en las áreas de las sierra y que estén dispuestos a participar en la iniciativa propuesta por el gobierno ecuatoriano.

Las importaciones procedentes de importantes países que se dedican a la elaboración de vinos, tales como: Argentina Estados Unidos, Canadá, Italia, Francia, entre otros, han tenido una notable disminución en nuestro país debido al incremento de salvaguardias y al aumento de manufacturación en la provincia de Santa Elena y en zonas de la región interandina.

Según las estadísticas no se cuenta con registros de que se tengan plantaciones de uva en la región Sierra, sin embargo de acuerdo a datos obtenidos del MAGAP las siguientes provincias a mencionar son: Guayas, Manabí, El Oro, Pichincha, Loja y algunos valles ubicados en la Sierra, pueden dar cosechas de calidad y lo que es más relevante es que se lo puede realizar en varias épocas durante todo el año, esto se debe a sus características climáticas y condicionantes en lo que respecta al tipo de suelo.

\section{MATERIALES Y MÉTODOS}

Explica que es imposible el desarrollo de cualquier ciencia, tanto desde la perspectiva de la investigación como de la transmisión de sus conocimientos, sin el empleo conjunto y complementario de ambos métodos.

El método inductivo- deductivo es el que a partir de casos particulares, se aumenta a conocimientos generales. Este método permite la formación de hipótesis, investigación de leyes científicas y las demostraciones. Y que estos sin haber ocurrido aún puedan ser explicados, entendidos y pronosticados.

"El método histórico lógico de investigación se aplica a la disciplina denominada historia, y además, se emplea para asegurar el significado y confiabilidad de hechos pasados en las ciencias en forma general y en cualquier disciplina científica. El método histórico ayuda a establecer las relaciones presentes en los hechos acontecidos en el desarrollo de las ciencias"

El método histórico- lógico nos permite establecer una manera de evaluar y analizar pruebas con la finalidad de obtener hechos, aspectos y antecedentes históricos para conocer la relación que existe entre las ciencias desde sus comienzos, de esta forma llegar a conclusiones acerca de hechos pasados que puedan explicar las conexiones y que nos guíen a entender y encontrar evidencias que respalden el presente 


\section{RESULTADOS}

Según las encuestas realizadas en una muestra aleatoria de 30 personas es posible deducir que todas estas personas han bebido vino alguna vez en su vida, aunque la frecuencia con que lo hacen es muy poca es decimos gran mayoría solo lo bebe en ocasiones especiales. Los encuestados también contestaron que Ecuador realmente necesita publicitar más el viniturismo y fomentar la cultura vitivinícola ecuatoriana, también el $73 \%$ ha escuchado o conocido de algún viñedo y el $63 \%$ conoce de la Hacienda Dos Hemisferios saben que se dedica a cosechar uvas y elaborar vinos, sin embargo al momento de preguntarles si saben de algún premio ganado solo el $27 \%$ sabía que si lo habían hecho, pero a pesar de esto cuando se les pregunto si podían nombrar alguno, ellos no sabrían responder a esta pregunta.

\section{DISCUSIÓN}

De acuerdo a los hechos observados y la encuesta realizada la cultura vitivinícola ha estado presente en nuestro país desde tiempos coloniales y sin embargo actualmente no es tan conocida como probablemente lo fue en el tiempo en que fue introducido el consumo del vino en Ecuador. Según los resultados y el análisis obtenidos en base a las encuestas realizadas es seguro decir que la población ecuatoriana necesita tener más culturalización en cuanto al enoturismo y todo lo relacionado al mismo, tal vez la falta o escasa cultura vitivinícola en nuestra sociedad se deba al hecho de lo "escandaloso" de esta, ya que pueden tener malos entendidos o no tener una mente abierta y solo se enfocan en que el vino es dañino al ser un licor, cuando en realidad es todo lo contrario. El vino tiene propiedades muy beneficiosas en nuestra salud, pero no solo eso, está bebida también es arte y cultura, con una gran riqueza histórica, es por esta razón que la cultura vitivinícola debe ser más comercializada en nuestra sociedad.

\section{Referencias}

Ortiz, C. (2013). Ecuador, Perú, Inglaterra, India, etc., considerados hoy como paises de nuevas latitudes, tienen un gran potencial vitivinicola. Argentina: Área del Vino. Recuperado de http://areadelvino.com/articulo.php? num $=25705$

Cata del vino (6 de octubre de 2017). Cultura del vino. Recuperado de http://www.catadelvino.com/blog-cata-vino/crece-lacultura-del-vino-en-ecuador

Chaupi Estancia Winery. (s.f.). Nosotros.Ecuador: MetaMorf Net Media. Recuperado de http://www.chaupiestancia.com/espanol/nosotros.html

Chaupi Estancia Winery. (s.f.). Vinos. Ecuador: MetaMorf Net Media. Recuperado de http://www.chaupiestancia.com/espanol/vinos.html

Chaupi Estancia Winery. (s.f.). Bodega. Ecuador: MetaMorf Net Media. Recuperado de http://www.chaupiestancia.com/espanol/bodega.html 
Chaupi Estancia Winery. (s.f.). Viñedo. Ecuador: MetaMorf Net Media. Recuperado de http://www.chaupiestancia.com/espanol/vinedo.html

Chaupi Estancia Winery. (s.f.).Tours. Ecuador: MetaMorf Net Media. Recuperado de http://www.chaupiestancia.com/espanol/tours.html

Definición ABC. (s.f.). Definición de viñedos. Recuperado de https:// www.definicionabc.com/general/vinedo.php

Diario EXPRESO (25 de agosto de 2016). 'Petróleo' en el paladar. Diario Expreso. Recuperado de http://expreso.ec/actualidad/ ydespuesdelaseleccionesahoraqueCB5 42400

Castro, R. (9 de enero de 2017). El vino local seduce los paladares ecuatorianos.Expreso. Recuperado de http://expreso.ec/economia/ elvinolocalseducelospaladaresecuatorianosAG998615

Edysma. (2013). Uva: Historia, Producción, Comercio. Italia: Edysima. Recuperado de http://www.zipmec.com/es/uva-historia-produccioncomercio.html

El Telégrafo (8 de febrero de 2014). Ecuador consume 16 millones de kilos de uva anualmente. El Telégrafo Recuperado de https://www.eltelegrafo.com.ec/noticias/economia/8/ ecuador-consume-16-millones-de-kilos-de-uva-anualmente

Jarrín, M.C. (3 de mayo de 2015). La alquimia del vino. El Telégrafo. Recuperado de https://www.eltelegrafo.com.ec/noticias/ buen/1/la-alquimia-del-vino

Millán, G., Morales, E., y Castro Freire, M.A. (2012). El turismo del vino: una aproximación a las buenas prácticas. TURyDES. 5(12). Recuperado de http://www.eumed.net/rev/turydes/12/tff.html

Eumed (diciembre de 2011). Vid, vino, y cultura occidental. Ecuador: Eumed. Recuperado de http://www.eumed.net/rev/cccss/16/jasp.html

La conversación (17 de diciembre de 2017). El acuerdo comercial con Europa despertó el boom de los vinos en Ecuador. Ecuador: La Conversación. Recuperado de https://laconversacion.net/2017/12/el-acuerdocomercial-con-europa-desperto-el-boom-de-los-vinos-en-ecuador/

Revista Líderes. (17 de septiembre de 2018). Vino de Yaruqui. Ecuador: Dialoguemos. Recuperado de http://www.revistalideres.ec/lideres/vinoyaruqui-cosecha-paladares-pais.html

González Lamas, R.M. (22 de enero de 2014). El vino en Ecuador. Puerto Rico: GRF Media Recuperado de https://www.sal.pr/2014/01/22/vinoen-ecuador/

Tour y vino. (2017). ¿Qué es el vino? Ecuador. Morgan Recuperado de https:// www.touryvino.com/el-vino/que-es-el-vino/ 